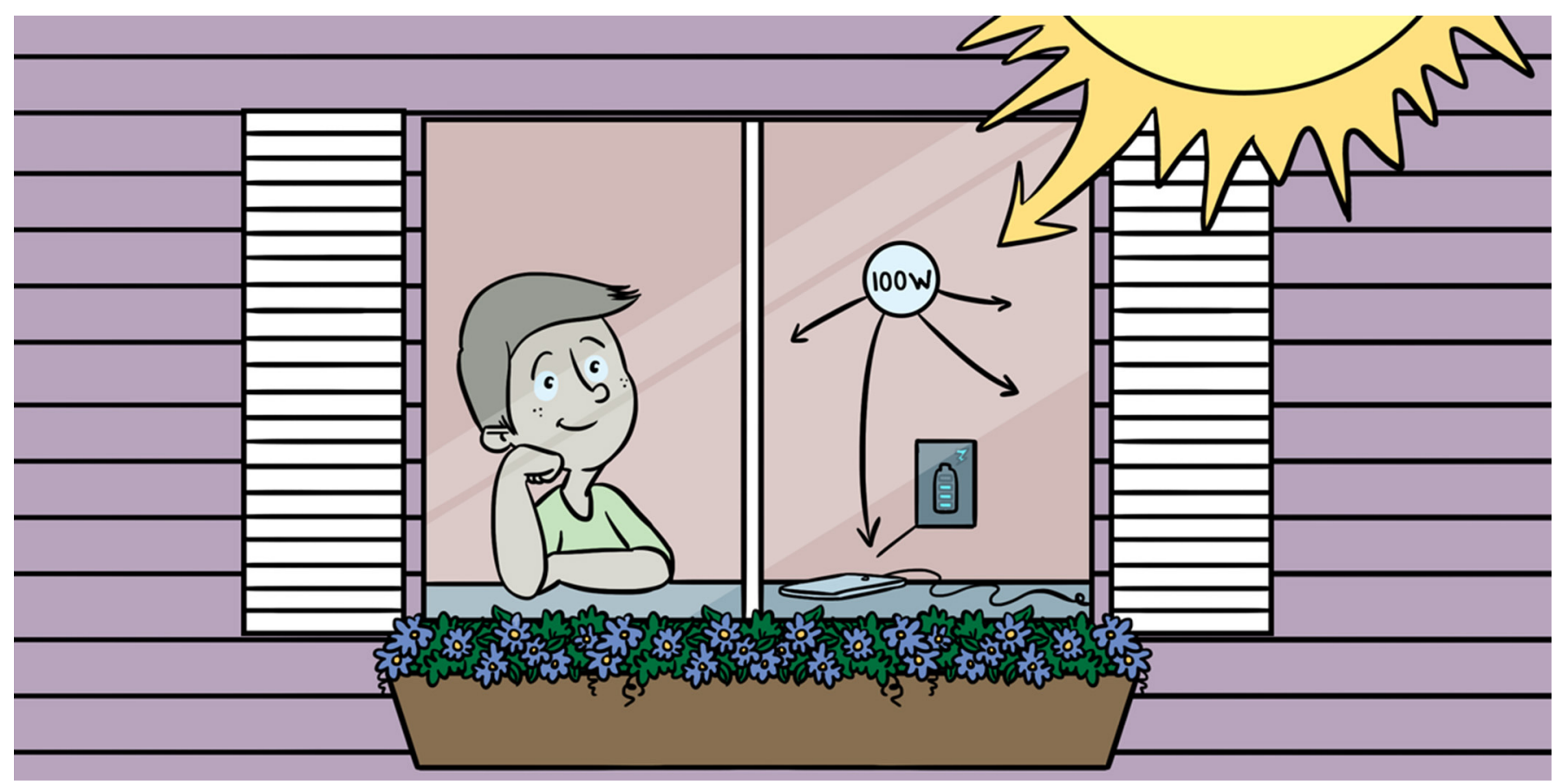

\title{
COLORLESS WINDOWS THAT TRANSFORM SUNLIGHT INTO ELECTRICITY
}

\section{Varun Vohra * and Takashi Sano}

Department of Engineering Science, The University of Electro-Communications, Chofu, Japan

\section{YOUNG REVIEWERS:}

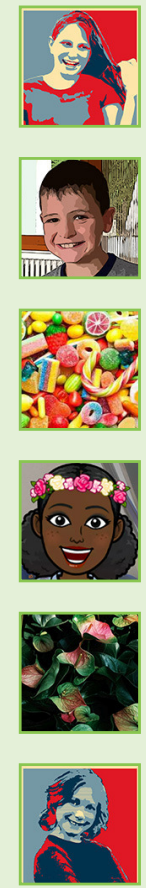

ADDY

AGE: 12

OLIVER

AGE: 10

PRICE

AGE: 13

PRINCESS

AGE: 15

PROVIDENCE

AGE: 10

TEDDY

AGE: 10
Solar cells help us use less coal or oil when we make electricity. This way, we cause fewer problems for the environment. Most solar panels are expensive, and they cannot be used for windows because they are not transparent, so they hide your view. But solar windows can be created with special chemicals called organic colorants. These windows can catch sunlight and use its energy to make electricity, but you can still see a beautiful view through them. The windows we made are inexpensive and keep the colors of your view unchanged. Each colorless window makes 100 watts of electricity, which is enough to recharge 20 smartphones at the same time. Because we can use these cheap, colorless, solar windows everywhere, we could make a lot of clean energy!

\section{USING SUNLIGHT AS A CLEAN ENERGY SOURCE}

A lot of people live on Earth. These people use phones, televisions, computers, and many other devices that need electricity to work. The most common way to make electricity is to burn coal, gas, or 
Figure 1

Mount Fuji is the tallest and most beautiful mountain in Japan. Everybody loves to look at it. (A) Silicon solar panels can hide Mount Fuji because they act like mirrors. If these panels were used as windows, you would not be able to see through them.

(B) When we look at Mount Fuji through a solar window made with the organic colorant $\beta$-carotene, the view through the window appears orange [2], but with the red colorants we use here, the view appears red [3].

\section{ORGANIC \\ COLORANT}

A chemical substance, made with carbon atoms, that can catch sunlight. Colorants give colors to objects like food, tree leaves, or even your skin.

\section{ACTIVE LAYER}

The very thin sheet in solar windows that catches light and transforms it into electricity.

\section{ELECTRODE}

A metal sheet that is used to catch or release electrons.

\section{ELECTRON}

Small particle with a negative electrical charge. The movement of electrons from one place to another makes an electrical current (electricity).

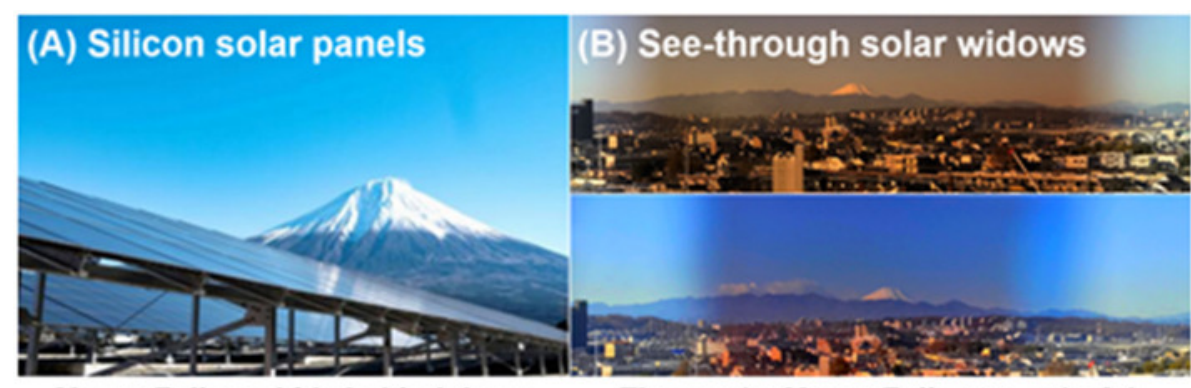

Mount Fuji can hide behind them

They make Mount Fuji more colorful

Figure 1

oil. Burning these fuels is a problem, because they release gases like carbon dioxide and methane when burned. These gases make our planet warmer and create other environmental problems. Because of this, many countries want to create electricity from clean energy sources, like sunlight [1]. To do this, we need solar panels. Typical solar panels are made with a material called silicon, which can capture sunlight. Silicon is expensive, so it is difficult to put many solar panels in poor countries. Also, silicon does not let light pass through it, so silicon solar panels cannot be used for windows, because they will hide your beautiful views (Figure 1A).

Luckily, there are many other colored chemical substances (called colorants) that can capture sunlight. When these colored substances include carbon atoms, we call them organic colorants. You can find some organic colorants in nature. For example, chlorophyll is the colorant that gives plants their green color, and $\beta$-carotene is the colorant that makes carrots look orange. We used natural or artificial organic colorants to create colorless solar windows. The structure of our solar window is shown in Figure 2. First, we made very thin sheets of organic colorant that are 1,000 times thinner than paper $[2,3]$. We call these sheets active layers. We must mix at least two colorants into the active layers if we want them to change sunlight into electricity. We sandwich one active layer between two other sheets, called electrodes, which catch or release electrons from or into the active layer. Electrons are small particles which create electricity when they flow from one electrode to the other. If the two electrodes are also transparent, solar windows will be see-through (Figure 1B). These windows make electricity from less than half of the sunlight that hits them, while they let the rest of the light pass through, so you can still see beautiful views through the solar windows.

While this may sound like an exciting breakthrough, there are two big problems with these windows. First, they eventually stop working because the oxygen in the air breaks down many organic colorants. Second, if the organic colorants do not catch all the colors of light equally, the view through the windows will look orange or red. Is it possible to make solar windows that last for a long time and that do 
Figure 2

See-through solar windows contain an active layer sandwiched between two electrodes. When sunlight hits the window, the colorants in the active layer catch photons and use their energy to create electrons that can freely move from one place to another. The electrodes show the electrons in which direction they should flow and the electron flow produces electricity.

\section{ELECTRICAL CURRENT}

Flow of electrons from one electrode to another that makes electricity.

\section{PHOTON}

A light particle. Photons with different energies have different colors.

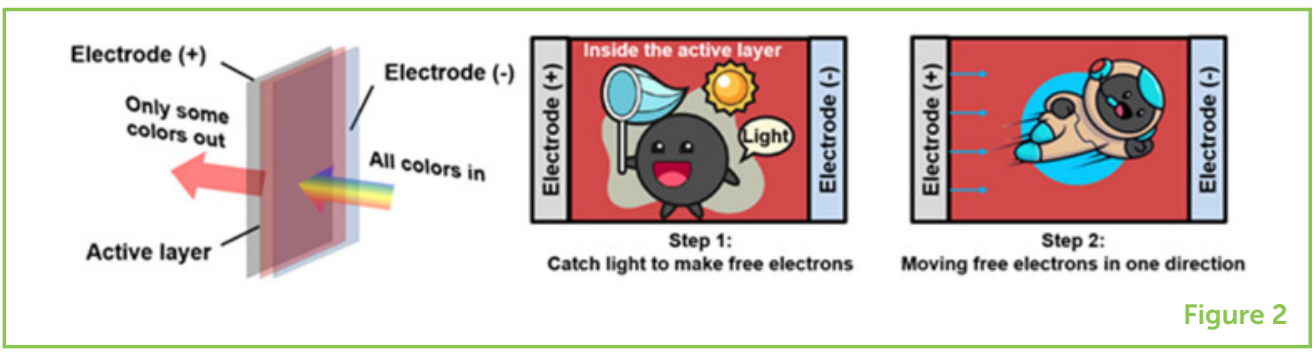

not change the color of your view? This is what we tried to do in our research.

\section{HOW DO SOLAR WINDOWS WORK?}

To make electricity, small particles called electrons must be made to move from place to place. This flow of electrons is called an electrical current. Electrons have a negative charge, so they are usually found stuck firmly to atoms, because particles called protons within atoms have a positive charge. As you probably know, opposite charges attract each other, while similar charges repel each other. To create a flow of electricity, electrons must first be knocked free from the atoms they are attached to. Knocking the electrons free requires an input of energy. In our solar windows, the electrons are knocked free from the atoms of one colorant, let us call it colorant $A$, by the energy of sunlight. Once the electrons are knocked free, they are "stolen" by atoms of the other colorant, which we will call colorant B. The electron stolen by colorant B can move freely from place to place because colorant B already has electrons stuck firmly to the protons within its atom. The free electrons can now flow from one electrode to the other electrode, which creates electricity. This is the basis of creating electricity using organic solar windows.... but there are a few more details you need to know.

Sunlight, like all light, is made of small particles called photons. Photons with different energies appear to our eyes as having different colors. For example, photons of red light have less energy than photons of blue or green light. For an electrical current to be created, the energy of the photons hitting the atoms of the colorant must be strong enough to separate the electrons from the colorant atoms. If the photons do not have enough energy to knock the electrons free, they will pass through the window without helping to produce an electrical current.

Also, as we mentioned earlier, the active layer of our solar windows is sandwiched between additional layers, called electrodes. These additional layers are important because they show the electrons in which direction they should flow. The electrodes are also the materials to which you will connect the electrical equipment that you want to power with the sunlight. For example, if you want to recharge your 
Figure 3

(A) When we measured the amount of transmitted light through our red windows, we found that T\% was 20\% higher for red light than for green or blue light (red dotted line). When we added a third chemical that can catch red photons, T\% was approximately $60 \%$ for all three colors of light and the solar window was colorless. (B) Normal windows have a $\mathrm{T} \%$ of about $70 \%$, so the view through our solar windows appears a little darker but its colors do not change.

TRANSMITTED

LIGHT (T\%)

The percentage of light that passes through something, like a window.

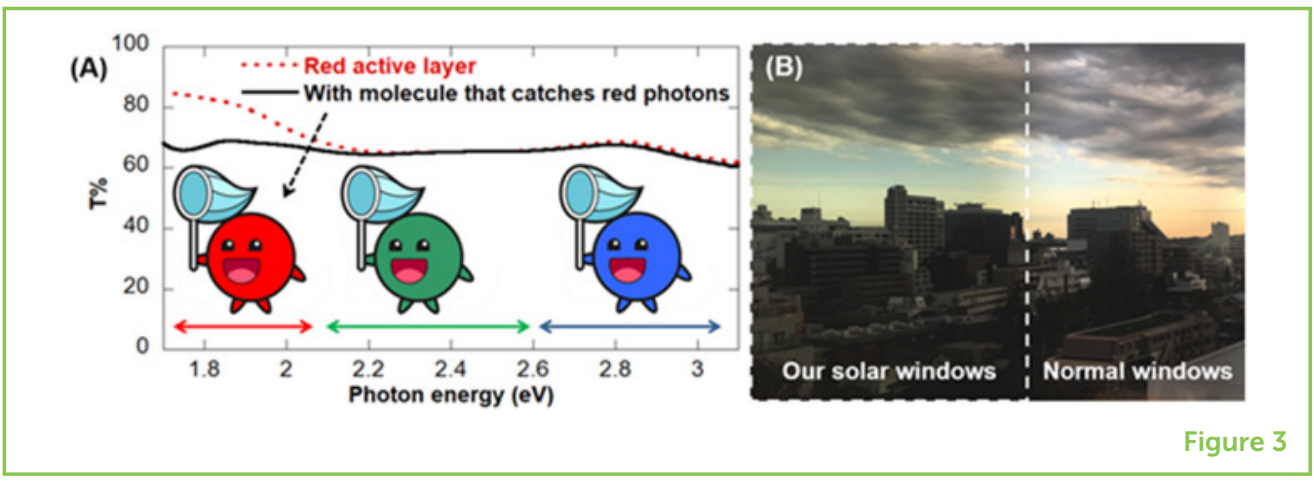

smartphone's battery, you will connect the battery's electrodes to the solar window's electrodes.

\section{HOW CAN WE MAKE COLORLESS SOLAR WINDOWS?}

Did you know that sunlight is made of many different colors? They are the colors you see in rainbows. The three primary colors are blue, green, and red (Some people say blue, yellow, and red, but we use green in science). Remember that the colors reflect the energy level of the photons. Some of the sunlight photons that hit a solar window will have enough energy to knock electrons off colorant atoms, causing an electrical current, but some photons will not. If they do not have enough energy to knock electrons off atoms, those photons will just pass right through the window-these photons are called transmitted light, and they make up the light that allows you to see through the window! We can calculate the percentage of transmitted light (T\%) as follows:

$\mathrm{T} \%=$ light that passes through the window/light that hits the window $\times 100 \%$

We created solar windows using two red organic colorants and then shined either red, blue, or green light on these windows to determine T\% for each color of light. When we tested solar windows made only with these two red colorants, we found that T\% was 20\% higher for red light than for blue and green light. This is because the red photons do not have enough energy to free electrons from the atoms of the red colorants in the active layer. The extra $20 \%$ of red light passes through the window and makes the window-and the view through the window-look red. We modified the active layers to contain a third colorant that can have its electrons knocked free by red photons. By doing this, we were able to make active layers that have a T\% of $60 \%$ for all three primary colors (Figure 3A). Those active layers are colorless because they transmit all the light that human eyes can see in the same amount, which makes the T\% graph look like a horizontal line. 
However, even with the proper mix of the three primary colors, the actual T\% for our solar window is about $43 \%$, because the components in the electrode layers decrease the amount of light that is transmitted. The T\% of normal windows is around $70 \%$. This means that our solar windows will look a little darker than normal windows (Figure 3B), but the advantage is that they can transform about $4 \%$ of the sunlight that hits them into electricity!

\section{CAN SOLAR WINDOWS MAKE ENOUGH ELECTRICITY?}

When we calculate how much electricity we use or make, we use a unit called watts $(W)$, which is a measure of electrical power. The power that we receive from sunlight over an area of $1 \mathrm{~m}^{2}$ is 1,000 W. Our solar windows are usually $1.9 \mathrm{~m}$ tall and $1.3 \mathrm{~m}$ wide, and they can generally change $4 \%$ of the solar power into electricity. Let us calculate how much electricity one solar window can make:

Window area: $1.9 \mathrm{~m} \times 1.3 \mathrm{~m}=2.47 \mathrm{~m}^{2}$ (let us round this up to $2.5 \mathrm{~m}^{2}$ )

Using the area, the solar power received by one window becomes: 2.5 $\mathrm{m}^{2} \times 1,000 \mathrm{~W} / \mathrm{m}^{2}=2,500 \mathrm{~W}$

Thus, the electricity made by one window is: $2,500 \mathrm{~W} \times 4 \%=2,500 \mathrm{~W}$ $\times 0.04=100 \mathrm{~W}$

Flat-screen televisions use around $90 \mathrm{~W}$ of electricity. You can charge a phone with $5 \mathrm{~W}$ and a tablet with $12 \mathrm{~W}$. For laptops, you need around $50 \mathrm{~W}$. So, if you have 1 television, 2 laptops, 1 tablet and 2 phones in your homes, you will need: $90 \mathrm{~W}+(2 \times 50 \mathrm{~W})+12 \mathrm{~W}+(2 \times 5 \mathrm{~W})=$ $212 \mathrm{~W}$. With 3 solar windows, you could easily use all those electronics at the same time! But wait...What if your microwave uses 500 W? This means that 5 windows would be needed to make it work. Can we make $500 \mathrm{~W}$ solar windows? Right now, it is difficult to make $500 \mathrm{~W}$ windows that have a T\% over 40\%, meaning these windows would make your view quite dark. We are now testing new colorants to make $250 \mathrm{~W}$ windows with a T\% of around $40 \%$. With only two of these windows, we could power a $500 \mathrm{~W}$ microwave!

Most people usually use microwaves for 5 or 10 min each day, so there are times when our solar windows would make more electricity than is needed. Batteries can be used to store excess electrical power for later use. If we use solar windows and batteries together, we should be able to power all the electronics in our homes. The electricity stored in batteries can also be used to power our electronics at night, or when there is no sunlight. 


\section{SUMMARY}

Using active layers that contain three colorants, we were able to fabricate solar windows that transmit around $40 \%$ of the light through them without changing the colors of the view you are looking at. Each of these windows can make around $100 \mathrm{~W}$ and we are working on ways to make more power from a single window. The organic solar windows are cheap and do not disturb your view, which means that they can be installed everywhere to power electrical equipment. As our society is using more and more electrical power, solar windows will be a key technology to make sure we can power our modern society without causing environmental problems.

\section{ORIGINAL SOURCE ARTICLE}

Sano, T., Inaba, S., Vohra, V. 2019. Ternary active layers for neutral color semitransparent organic solar cells with PCEs over 4\%. ACS Appl. Energy Mater. 2:2534-40. doi: 10.1021/acsaem.8b02144

\section{REFERENCES}

1. Renewable Energy Policy Network for the 21st Century (REN21). 2019. Renewables 2019 Global Status Report. Available online at: https://www.ren21. net/reports/global-status-report/

2. Vohra, V., Uchiyama, T., Inaba, S., and Okada-Shudo, Y. 2019. Efficient ultrathin organic solar cells with sustainable $\beta$-carotene as electron donor. ACS Sustain. Chem. Eng. 7:4376-81. doi: 10.1021/acssuschemeng.8b06255

3. Inaba, S., Arai, R., Mihai, G., Lazar, O., Moise, C., Enachescu, M., et al. 2019. Eco-friendly push-coated polymer solar cells with no active material wastes yield power conversion efficiencies over 5.5\%. ACS Appl. Mater. Interfaces 11:10785-93. doi: 10.1021/acsami.8b22337

SUBMITTED: 16 April 2020; ACCEPTED: 14 July 2021;

PUBLISHED ONLINE: 06 August 2021.

EDITED BY: Anna Regoutz, University College London, United Kingdom

CITATION: Vohra V and Sano T (2021) Colorless Windows That Transform Sunlight Into Electricity. Front. Young Minds 9:552439. doi: 10.3389/frym.2021.552439

CONFLICT OF INTEREST: The authors declare that the research was conducted in the absence of any commercial or financial relationships that could be construed as a potential conflict of interest.

COPYRIGHT () 2021 Vohra and Sano. This is an open-access article distributed under the terms of the Creative Commons Attribution License (CC BY). The use, distribution or reproduction in other forums is permitted, provided the original author(s) and the copyright owner(s) are credited and that the original publication 

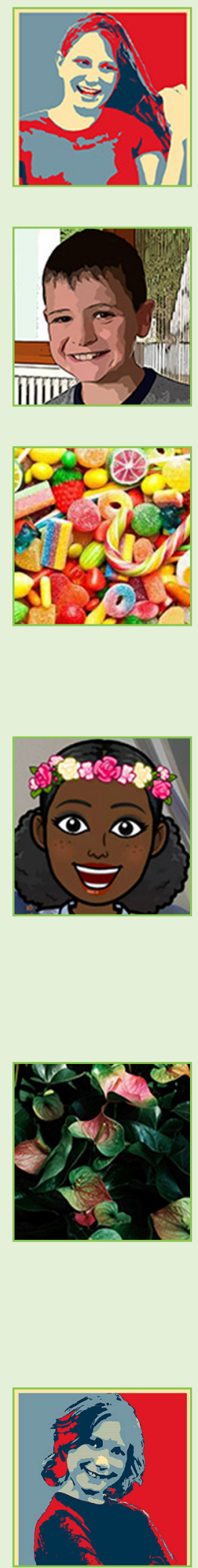

in this journal is cited, in accordance with accepted academic practice. No use, distribution or reproduction is permitted which does not comply with these terms.

\section{YOUNG REVIEWERS}

\section{ADDY, AGE: 12}

I am in the 7th grade and really enjoy volunteering at my local museum. I really like helping animals and I hope to become a veterinarian when I get older. My favorite class in school is my dance class (I am very flexible), and I love to travel.

\section{OLIVER, AGE: 10}

Oliver loves science and is very curious. As he lived in different countries (Ireland, England, and now Switzerland), he is fluent in 4 languages already and would like to travel the world some more when he gets older.

\section{PRICE, AGE: 13}

Price loves making up stories and has also written a book (Ms. Wasteson and the waste empire). She enjoys gymnastics, athletics, volleyball, and basketball. She is brave and bouncy. Price also enjoys quality time with family and is very creative. At her school, she is part of a "green team" that works to protect the environment. She likes debating and has a passion to study and become an activist against social injustices.

\section{PRINCESS, AGE: 15}

Princess has many ideas and goals and is passionate about helping others to be better. She is a deep thinker while solving problems. Princess is funny, sporty, jumpy, and a kind person, who loves exploring to find solutions. She is creative, narrative, and likes writing. Princess wrote a book titled "Sarah and the waste center." She loves learning new things. She is into volleyball, music, band, art, and digital photography. Her purpose is to learn more about science, and to improve her writing and editing skills.

\section{PROVIDENCE, AGE: 10}

Providence is the youngest amongst her three sisters. She is playful and bouncy. Providence is curious, talkative, and likes asking many funny questions, that leaves others laughing. She loves making new friends and traveling. Providence loves science experiments. During this process, she may destroy, repair, or recycle some household items. As part of this adventure, Providence repaired a spoilt speaker. But after weeks of action, she modeled the speaker wires into skipping ropes. She is passionate about music and sports including volleyball.

\section{TEDDY, AGE: 10}

I want to be an engineer. I have really enjoyed trying and struggling to learn how to engineer and code things. I am dyslexic. I really love maths (especially algebra and geometry). I like to travel. I bike 30 miles a week most weeks. 


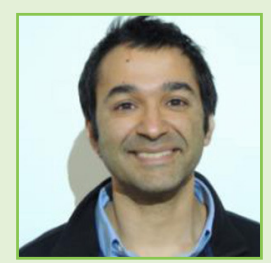

\section{AUTHORS}

\section{VARUN VOHRA}

When people ask me what I do for a living, I often reply, "I try to save the planet, but not like superman." Science does not give me superpowers, but it helps me understand why some very special plastics or other organic materials can conduct electrical charges. Using these special organic materials, I make very thin solar cells that can be transparent or flexible. I try to understand how to improve their performance, to help us move toward a more energy-sustainable future. *varun.vohra@uec.ac.jp

\section{TAKASHI SANO}

My interest in semiconductors started when I was a teenager. Because of this, I joined the University of Electro-Communications in 2015. Under the supervision of associate professor Vohra, I discovered an amazing new technology: solar cells that are see-through and that you can bend or stretch. Once you finish playing with them, they go back to their original shape-and they still work! I hope that our results will raise your interest, so that you might join the next generation of scientists working on organic solar cells. 